\title{
The sunflower seeds oil extraction: the mechanism and kinetics of the process
}

\author{
Oksana Dobrovetska, Yevgen Semenyshyn, Roman Stadnyk, Volodymyr Atamanyuk, \\ Oleksandr Ivashchuk
}

Department of Chemical Endineering, Lviv Polytechnic National University, UKRAINE, Lviv, 12 S.Bandera street, E-mail: oksanadobrovetska@gmail.com

Abstract-The results of the research of extracting oil from sunflower seeds by the method of extraction are given. The kinetics and mechanism of the extraction process investigated. It is shown that the process of extracting sunflower seed oil is complicated and include as intra-diffusion and outer-diffusion oil transfer is similar to extraction of target components from other seeds of plant material (amaranth, rapeseed, etc.). The technique of experimental calculation of the diffusion coefficient is given and the slowest stage of the extraction process is determined, which determines the speed of the whole process.

Keywords - extraction, plant raw materials, mechanism and kinetics of process.

\section{Introduction}

The extraction process of target components from plant raw materials is widely used in various industries, especially in food, pharmaceutical, chemical, petroleum, and others. The large demand to agrarian business in Ukraine is a sunflower, which, depending on the natural environment, contains up to $60 \%$ of the oil. Sunflower is a base of the agricultural crop because it contains, in addition to oils, protein and other target components which used in the pharmaceutical, chemical, perfumery, and other industries. It should be emphasized that Ukraine exports sunflower oil to over than 100 countries of the world, which requires more efficient technologies for its production for the purpose of providing with world demand.

For today, there are two methods of extracting oil plant raw materials: press and extraction. The advantage of the extraction method is the high degree of oil extraction of $97-98 \%$, the use of simple equipment and lower energy consumption, compared with the previous method.

The process of extracting the target components from plant raw materials is rather complicated. The complexity of this process is related to the cellular structure of the raw material and the presence of a poorly-permeable shell in the seeds of plants, and also in that, the target component moving within the seed to the surface of the phase contact with the solvent must overcome a number of barriers associated with the complex structure of the seed. The entire process should be considered as intra-diffusion, outer-diffusion and mixed since diffusion is the basis of these processes.

For study and the establishment of a mechanism for the extraction oil process of sunflower seed is used the equation obtained by the method of integral ratios for the extraction processes of the target components from the plant raw material [1-2].

For a mathematical description of the extraction process adopted the physical model of seed in the form of a ball in the pores of which is the target component, has the form:

$$
\tau=\frac{1}{6}-\frac{\varphi_{0}^{2}}{2}+\frac{\varphi_{0}^{3}}{3}+\varepsilon \cdot\left(1-\varphi_{0}\right)+\frac{1}{3 \cdot B i} \cdot\left(1-\varphi_{0}^{3}\right)
$$

For the mixed-diffusion mechanism $(\varepsilon \rightarrow \infty)$ the equation $(1)$ is reduced to the form:

$$
\tau=\frac{t}{T}=\frac{1-3 \cdot \varphi_{0}^{2}+2 \cdot \varphi_{0}^{3}+\frac{2}{B i} \cdot\left(1-\varphi_{0}^{3}\right)}{1+\frac{2}{B i}}
$$


The value of $\varphi_{o}$ which corresponds to a certain extraction time $t$ is determined from the material balance:

$$
G_{0} \cdot\left(1-\varphi_{0}\right)=W C
$$

The value of $\varphi_{o}$ changes from 1 to 0 for, for $\mathrm{t}=0{ }^{\circ} \mathrm{C}, \varphi=1$. To establish the mechanism of extraction, it is necessary to identify the experimental studies of the extraction kinetics in the form of function $\mathrm{C}=f(\tau)$.

For the intra-diffusion mechanism, there must be a linear dependence. Such dependence exists, while it is possible to determine the diffusion coefficient $-\mathrm{D}$ and the total time $\mathrm{T}$. The diffusion coefficient is determined over the tangent angle of the slope $\Phi=f(t)$

$$
D=\frac{R^{2} \cdot C_{1}}{\rho} \cdot \operatorname{tg} \alpha
$$

The value of the Bio ( $\mathrm{Bi})$ criterion can be determined using the linearization method of equation (1) by introducing a new function $y$ and argument $a$ :

$$
y=\frac{1-\frac{t}{T} \cdot \frac{1}{1-\varphi_{0}}}{\varphi_{0} \cdot\left(1-\varphi_{0}\right)} ; \quad x=\frac{2 \varphi_{0}}{\left(1-\varphi_{0}\right)} ;
$$

then the equation (1) is converted into a linear $y=A x+B$

where $\quad A=\frac{1}{1+\frac{6}{\varepsilon}+\frac{2}{B i}} ; \quad B=\frac{\frac{2}{B i}}{1+\frac{6}{\varepsilon}+\frac{2}{B i}}$

Thus, the technique for determining the $\mathrm{Bi}$ criterion and $\varepsilon$ is reduced to the transformation of equation (1) into a linear, sequential definition of the constants $\mathrm{A}$ and $\mathrm{B}$, from which the criteria of Bi and $\varepsilon$ are determined.

Experimentally we investigated the kinetics of extraction of oil from shredding sunflower seeds n-hexane $\left(t=69^{\circ} \mathrm{C}\right)$ in Soklet apparatus for different mean grain diameters $\mathrm{d}_{\text {aver }}=0.7$ $\mathrm{mm}, \mathrm{d}_{\mathrm{aver}}=0.5 \mathrm{~mm}, \mathrm{~d}_{\mathrm{aver}}=0.25 \mathrm{~mm}$. The research results showed that this process passes by a mixed mechanism (outer- and intra-diffusion mechanism). Also, the value of the diffusion coefficient was determined by equation (4), which is $\mathrm{D}=1.5 \cdot 10^{-12} \mathrm{~m} / \mathrm{s}$.

\section{Conclusion}

Experimentally we investigated the kinetics of extraction of oil from shredding sunflower seeds. The research results showed that this process passes by a mixed mechanism.

\section{References}

[1] Ye. M. Semenyshyn, T.I. Rimar, "Intensification of Process and Kinetics of Extraction of Target Components from Vegetable Raw Materials", Visnyk Natsional'noho universytetu "L'vivs'ka politekhnika". Khimiya, tekhnolohiya rechovyn ta yikh zastosuvannya, Vol. 868, pp. 298-303, 2017.

[2] Ye. M. Semenyshyn, V. I. Trotsky, M. I. Matyusovska, R. V. Stadnyk, "Kinetics of extraction of oil from amaranth seeds and rapeseed under the conditions of a moving layer", Scientific works of the Odessa National Academy of Food Technologies, vol. 41, no 1, pp. 128-133, 2012. 